\title{
HSV2 acute retinal necrosis: diagnosis and monitoring with quantitative polymerase chain reaction
}

\author{
L. Cottet $\cdot$ L. Kaiser $\cdot$ H. H. Hirsch $\cdot$ E. Baglivo
}

Received: 11 December 2007 / Accepted: 22 January 2008/Published online: 23 February 2008

(C) Springer Science+Business Media B.V. 2008

\begin{abstract}
Purpose To describe a case of HSV2 acute retinal necrosis (ARN) diagnosed and monitored with quantitative polymerase chain reaction (PCR) in ocular fluids. Design Case report. Methods Quantitative PCR was performed in the aqueous humor (AH) and vitreous using primers specific for herpes virus. Results A positive PCR was found for HSV2 in the AH $(>100,000,000$ viral copies $8.00 \mathrm{log} / \mathrm{ml})$. After therapy, another anterior chamber tap showed a reduction of the viral load at $4.28 \mathrm{log} / \mathrm{ml}$ (19205 copies), confirming the efficacy of the treatment. After six months, PCR on the vitreous still showed the presence of HSV2 viral particles in the eye (3.14 log DNA copies/ml, 1379 copies) although the lesion was healed. Conclusions This case demonstrates that PCR is useful to detect viral DNA in $\mathrm{AH}$ and vitreous and to monitor viral activity and
\end{abstract}

L. Cottet · E. Baglivo $(\square)$

Clinique d'Ophtalmologie-Uveitis Department,

Hôpitaux Universitaires de Genève, Rue Alcide-Jentzer,

22, 1205 Geneva, Switzerland

e-mail: Edoardo.Baglivo@hcuge.ch

L. Kaiser

Laboratoire central de virologie, Service des maladies infectieuses HUG, 1211 Geneve 14, Switzerland

H. H. Hirsch

Division of Molecular Diagnostics,

Clinical and Transplantation Virology, Institute for Medical Microbiology, Petersplatz 10, 4003 Basel,

Switzerland therapeutic response. Viral DNA persists in ocular fluids for months in the presence of a healed infection.

Keywords Acute retinal necrosis . PCR · HSV2 - Aciclovir · Uveitis

\section{Introduction}

A 31-year-old South-American woman was referred for acute and progressive visual loss affecting her left eye (LE), with diffuse ocular pain, photophobia, and redness.

Examination revealed a visual acuity of 20/100 in LE and 20/20 in right eye (RE) without correction. Anterior segment disclosed a mild nongranulomatous inflammation in the LE. Intra-ocular pressure was $10 \mathrm{mmHg}$ in both eyes. Fundus examination of the LE revealed a vitritis ( $3+$ cells), a disc edema, occlusive vasculitis, and areas of inferior retinal necrosis (Fig. 1). An acute retinal necrosis (ARN) was suspected and the patient was hospitalized.

An anterior chamber tap was then performed for Herpexvirus1 (HSV1), Herpesvirus2 (HSV2), Varicella-Zoster virus (VZV), Cytomegalovirus (CMV), Epstein-Barr virus (EBV), and Toxoplasmosis PCR. The patient was immediately treated with a combination of iv aciclovir $(3 \times 10 \mathrm{mg} / \mathrm{kg} / 8 \mathrm{~h})$ and oral valganciclovir $(2 \times 450 \mathrm{mg} / \mathrm{d})$ as well as one 


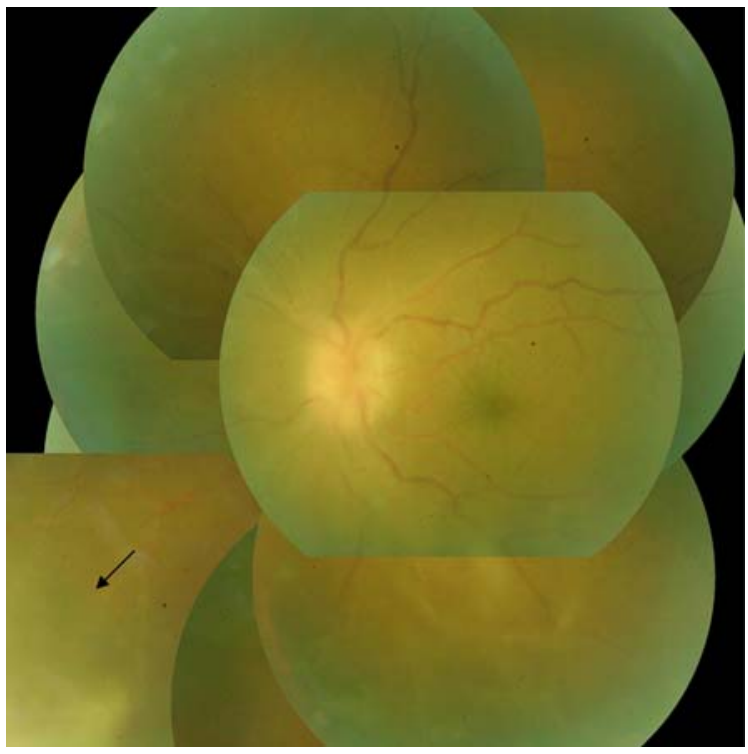

Fig. 1 Color picture of the left eye: optic nerve head edema, occlusive vasculitis, and area of retinal necrosis inferiorly (arrow)

intravitreous injection of ganciclovir $(2000 \mu \mathrm{g})$. Topical steroids and mydriatics were also prescribed.

Blood tests revealed a sedimentation rate of $8 \mathrm{~mm} / \mathrm{h}$ ( $\mathrm{N}=1-12)$, and a normal white blood count. An extensive uveitis work-up looking for infectious and noninfectious causes was negative, in particular serologies for borrelia burgdorferi, treponema pallidum, leptospirosis, rickettsiosis, brucellosis, and toxoplasmosis. Serologies for herpes virus revealed past exposure (HSV IgG 1.19, $\mathrm{N}<0.2$ and $\operatorname{IgM} 0.12$, $\mathrm{N}<0.2$ ).

Quantitative PCR analysis of the AH was positive for HSV $2>100,000,000$ viral copies $(8.00 \mathrm{log} / \mathrm{ml})$ and all other PCR tests were negative. After 2 weeks of therapy, we performed another anterior chamber tap and results showed a reduction of the viral load at $4.28 \mathrm{log} / \mathrm{ml}$ (19205 copies), confirming the efficacy of the antiviral treatment (Fig. 2).

Aciclovir treatment was continued for two additional weeks iv, then orally for 3 months. Valganciclovir $(2 \times 450 \mathrm{mg} /$ day $)$ was prescribed during the first 2 weeks. No systemic (blood count, renal function) or local adverse effects were observed. Complete cicatrization of the main necrotic lesion was noted. After 7 months, a vitrectomy was performed to clear the vitreous inflammatory opacification. PCR on the vitreous sample still showed the presence of HSV2 viral

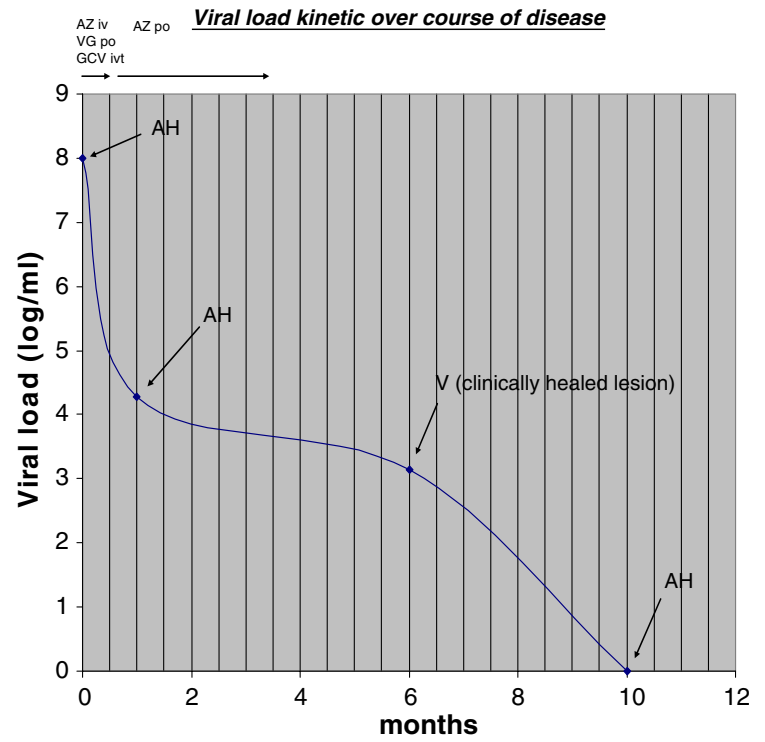

Fig. 2 Viral load kinetic over disease course. Abbreviations: AZ: aciclovir, VG: valganciclovir, GCV ivt: intravitreous ganciclovir, $\mathrm{AH}$ : aqueous humor, $\mathrm{V}$ : vitreous

particles in the eye (3.14 log DNA copies/ml, 1379 copies).

We followed the patient during 24 months. No ocular complications were recorded and no reactivation/bilateralization of the infection was observed. Final visual acuity was 1.0 in both eyes. Another anterior chamber tap, performed at 10 months, revealed negative herpes virus PCR.

\section{Comment}

ARN was first described by Urayama and associates in 1971 [1] and subsequently was shown to be most frequently caused by herpes simplex virus type 1 or 2 and less frequently by the varicella zoster virus. This infection has potentially devastating consequences on ocular function and is frequently complicated by secondary retinal detachment and bilateral involvement. The diagnosis is initially based on clinical features (areas of retinal necrosis, occlusive vasculitis, vitritis) [2]. ARN occurs both in immunosuppressed and apparently immunocompetent patients. A study has however shown that, even in patients thought to be immunocompetent, there is a degree of immune dysfunction [3]. The recommended treatment of ARN includes initial high dose of intravenous aciclovir 
$(3 \times 10 \mathrm{mg} / \mathrm{kg} / 8 \mathrm{~h})$ for 10 days followed by 3 months of oral suppressive treatment with aciclovir. Intravitreal therapy (ganciclovir, foscarnet), topical steroids, and mydriatics are considered useful as adjuvant therapy to control infection and inflammation. Although diagnosis is initially clinical, formally microbiological and particularly virological analysis of ocular fluids (AC and/or vitreous) is needed to identify the causative agent and guide therapy [4].

The possible involvement of a herpes-group virus as the causative agent of ARN was first suggested by Culbertson in 1982, after histopathological and electron microscopy evaluation of an enuclated eye [5]. In 2000, Ganatra et al. found in a group of 28 patients with ARN, HSV1 in 7 patients, HSV2 in 6 patients and CMV in one patient [6]. The association of ARN with herpetic encephalitis or disseminated herpes in the neonate has also been reported [7]. It has been suggested that, in patients under 25 years old, ARN is more likely to be caused by HSV2. Tran et al. [8] described 11 cases of HSV2-related ARN syndrome in patients aged from 10 to 57 years. At the end of the follow-up period, five eyes (41.7\%) showed improvement of visual acuity of two or more lines. Final visual acuity was $20 / 60$ or better in four eyes $(33.3 \%), 20 / 400$ or better in four eyes $(33.3 \%)$, and less than 20/400 in four eyes. In our patient, after a follow-up of 24 months, vision returned to 20/20 with no bilateralization and/or reactivation of the infection.

PCR is a sensitive and specific method performed for detection of viral DNA in ocular samples from immunocompetent and immunocompromised patients presenting with viral retinitis. It has been used as a tool for the determination of causal agents in ARN syndrome. In our case, results of the AH examination were positive for HSV2 with initially a very high viral load confirming the etiology.

Probably, the number of viral copies was higher in the vitreous. Interestingly, after introduction of the antiviral treatment a sharp and significant decrease of the number of viral copies was observed. At 6 months post treatment, at a time when the lesions were healed, a significant decrease of the number of viral copies was observed in the AH. A positive residual viral load at 1379 copies was still present in the vitreous. At 10 months PCR was negative in the AH. Our case demonstrates the utility of PCR for diagnosis and suggests that viral DNA persists in ocular fluids for months in the presence of a healed infection.

\section{References}

1. Urayama AYN, Sasaki T, Nishiyama Y, Watanabe H, Wakusawa S, Satoh Y, Takahashi K, Takei Y (1971) Unilateral acute uveitis with periarteritis and detachment. Jpn J Clin Ophthalmol 25:607-619

2. Holland GN (1994) Standard diagnostic criteria for the acute retinal necrosis syndrome. Executive Committee of the American Uveitis Society. Am J Ophthalmol 117(5):663-667

3. Rochat C, Polla BS, Herbort CP (1996) Immunological profiles in patients with acute retinal necrosis. Graefes Arch Clin Exp Ophthalmol 234(9):547-552

4. Oueghlani E, Baglivo E, Durakovic O, Safran AB (2005) Varicella-zoster virus retinitis: successful evolution with a combination of antiviral therapies. Klin Monatsbl Augenheilkd 222(3):264-266

5. Culbertson WW, Blumenkranz MS, Haines H, Gass DM, Mitchell KB, Norton EW (1982) The acute retinal necrosis syndrome. Part 2: Histopathology and etiology. Ophthalmology 89(12):1317-1325

6. Ganatra JB, Chandler D, Santos C, Kuppermann B, Margolis TP (2000) Viral causes of the acute retinal necrosis syndrome. Am J Ophthalmol 129(2):166-172

7. Kychenthal A, Coombes A, Greenwood J, Pavesio C, Aylward GW (2001) Bilateral acute retinal necrosis and herpes simplex type 2 encephalitis in a neonate. Br J Ophthalmol 85(5):629-630

8. Tran TH, Stanescu D, Caspers-Velu L, Rozenberg F, Liesnard C, Gaudric A et al (2004) Clinical characteristics of acute HSV-2 retinal necrosis. Am J Ophthalmol 137(5):872-879 